\title{
PROGRESSO NATURAL E AÇÃO POLÍTICA EM ADAM SMITH ${ }^{1}$
}

\author{
Alexandre Amaral Rodrigues*
}

Resumo: Este texto retoma questões propostas por Maria das Graças de Souza quanto a Jean-Jacques Rousseau e procura responder a elas no que se refere à obra de Adam Smith. Segundo a autora, no pensamento de Rousseau há duas concepções do tempo histórico: uma delas enquanto determinação (ou declínio) e outra enquanto "ocasião oportuna", ou o momento da ação política. Em Adam Smith, por outro lado, a história aparece como "progresso natural", e, portanto, determinação. Procuraremos mostrar, no entanto, que o autor concebe também a necessidade da ação política, embora com muitas restrições.

Palavras-chave: A. Smith - J-J. Rousseau - progresso natural - ação política.

Em seu texto Ocasião propicia, ocasião nefasta: Tempo, história e ação política em Rousseau², Maria das Graças de Souza identifica duas imagens clássicas de tempo na obra de Rousseau: tempo enquanto Kronos ${ }^{3}$, que a seus filhos devora, associado ao declínio da humanidade em sua trajetória desde a "rusticidade e simplicidade" até o "estado de civilização"; e tempo enquanto kairos ${ }^{4}$ ou ocasião oportuna, o momento da ação política, a qual pode constituir um passo a mais no declínio, o que seria a "ocasião nefasta", à qual se associam, por exemplo, a instituição da propriedade e a do governo, respectivamente, ou então a ação pode ir em sentido contrário ao declínio, de modo a caracterizar-se o momento, geralmente de crise aguda, como "ocasião oportuna", o "instante em que a ação coincide com o tempo e faz com que a ocasião seja propícia e a ação seja boa para a vida da república".

É por meio dessas categorias que Souza delineia em Rousseau os momentos da universalidade e da particularidade, a teoria, associada ao diagnóstico do declínio e suas causas universais, e a ação política benéfica à república, sempre dependente das configurações particulares dos povos e estados no tempo. Desse modo, a autora recusa, quanto ao filósofo genebrino,

Uma certa crítica contemporânea às concepções iluministas da história, segundo a qual estas concepções pecam pelo seu universalismo e pelo seu caráter abstrato, tomando, seja o gênero humano e sua totalidade, o que tem

\footnotetext{
${ }^{1}$ Texto desenvolvido em pesquisa com financiamento FAPESP. Apresentado no VIII Colóquio Nacional Filosofia da História: Tempo, História e Sociedade, São Paulo, 2015.

* Doutorando pelo Programa de Pós-Graduação em Filosofia da USP.

2 SOUZA, “Ocasião propícia, ocasião nefasta...”, pp. 249-256.

${ }^{3}$ SOUZA, “Ocasião propícia, ocasião nefasta...”, pp. 249-250.

${ }^{4}$ SOUZA, “Ocasião propícia, ocasião nefasta...”, p. 251.

${ }^{5}$ SOUZA, “Ocasião propícia, ocasião nefasta...”, p. 252.

' SOUZA, “Ocasião propícia, ocasião nefasta...”, p. 256.
} 
como resultado ignorar a particularidade dos povos, seja considerando os povos enquanto um todo harmônico, ocultando os conflitos e contradições no interior destes mesmos povos, e isto manifesta seu caráter ideológico. Esta crítica tem como alvo, sobretudo, as doutrinas do progresso, embora se dirijam à filosofia das luzes em geral. ${ }^{7}$

Ora, a obra de Adam Smith, como o mostra Christian Marouby ${ }^{8}$, dentre outros, se incluiria precisamente nesse caso, já que concebe a trajetória das sociedades do estado selvagem para o civilizado como um contínuo avanço em direção à opulência, e esta, como contínua acumulação de capital ou crescente aumento da riqueza das nações. Tal concepção cumularia na naturalização do "crescimento econômico" e do "desenvolvimento" ou "progresso" das nações".

Isso me motivou a questionar se as categorias por meio das quais Maria das Graças e Souza expôs o pensamento rousseauniano se aplicariam, e como, à obra de Adam Smith.

De fato, em suas Lectures on jurisprudence, Smith afirma haver "quatro estados distintos pelos quais passa a humanidade, primeiramente a Era dos Caçadores, em segundo lugar, a Era dos Pastores; em terceiro, a Era da Agricultura, e, em quarto, a Era do Comércio" "10. A passagem de uma a outra dessas eras, definidas segundo as ocupações principais por meio das quais se obtém a subsistência, é determinada pela capacidade, ou antes pela exaustão da capacidade de cada uma de prover àquela sociedade com o necessário para a sobrevivência. A multiplicação dos humanos vem a tornar, sucessivamente, cada uma delas, em certo momento, incapaz de sustentar-se, o que levaria, em longuíssimos períodos de tempo, à gradual passagem à outra.

De modo geral, Smith mostra uma avaliação positiva desse "progresso". Segundo ele, nesse estágio final, a sociedade teria exercido "toda a sua capacidade para alcançar a maior tranquilidade e a conveniência" ". Seu tom chega a ser entusiástico na introdução à Riqueza das nações, na qual afirma que

Entre nações selvagens de caçadores e pescadores, todo indivíduo capaz de trabalhar emprega-se, em maior ou menor grau, em trabalhos úteis, e busca ao máximo prover-se a si e (...) [aos incapazes] de sua família ou tribo com tudo o que seja necessário ou conveniente à vida. Tais nações, no entanto, são tão miseravelmente pobres que, por mera escassez (want), frequentemente são, ou ao menos julgam ser reduzidos à necessidade ora de eliminar diretamente, ora de abandonar à própria sorte suas crianças, velhos

\footnotetext{
7 SOUZA, “Ocasião propícia, ocasião nefasta...”, p. 255.

${ }^{8}$ MAROUBY, L'économie de la nature, 2004.

${ }^{9}$ MAROUBY, L'économie de la nature, pp. 220-221.

${ }_{10}$ SMITH, Lectures on jurisprudence, p. 14.

11 SMITH, Lectures on jurisprudence, p. 16.
} 
e doentes, para que pereçam de fome ou sejam devorados pelas feras. Ao contrário, entre as nações civilizadas e prósperas, embora um grande número de pessoas absolutamente não trabalhe, e consuma muitas vezes dez ou cem vezes mais $(. .$.$) do que a maior parte das que trabalham, ainda assim o$ produto de todo o trabalho da sociedade é tão grande que frequentemente todos são abundantemente supridos, e mesmo o trabalhador da mais baixa ordem, o mais pobre, se for frugal e industrioso, pode desfrutar de uma parcela maior do que é necessário ou conveniente à vida do que seria possível a qualquer selvagem ${ }^{12}$.

Nada poderia ser mais otimista do que essa descrição dramática das virtudes do avanço para a civilização e o comércio.

Mas nem tudo são flores. Em seu Esboģo de a riqueza das nações, redigido treze anos antes da obra final, a desigualdade, ainda que positiva, é pintada em cores bem mais fortes.

No que concerne ao produto do trabalho de uma grande sociedade, nunca há uma divisão justa e igualitária. Numa sociedade de cem mil famílias, haverá, talvez, cem delas que absolutamente não trabalham, e que, no entanto, seja por meio de violência, seja pela opressão mais ordenada da lei, usufruem de maior parcela do trabalho da sociedade do que dez mil outras famílias. E mesmo a divisão do restante após esse enorme desfalque não é de modo algum proporcional ao trabalho de cada indivíduo. Ao contrário, os que mais trabalham, menos ganham. O opulento mercador, que passa a maior parte do seu tempo em luxos e divertimentos, desfruta de uma proporção muito maior dos ganhos de seu comércio do que todos os funcionários e contadores que realizam os negócios. Estes, por sua vez, desfrutam de considerável tempo livre e quase não passam por outras agruras que não a do confinamento da atenção, e, no entanto, usufruem de uma parcela muito maior da produção do que um número três vezes maior de artesãos, os quais, sob sua direção, trabalham muito mais árdua e assiduamente. $\mathrm{O}$ artesão, por seu turno, embora trabalhe geralmente em locais cobertos, em segurança, ao abrigo das intempéries e convenientemente auxiliado por inúmeras máquinas, usufrui, no entanto, de um quinhão de riqueza muito maior do que o pobre trabalhador que tem de se debater com as dificuldades do solo e do clima, e que, ao mesmo tempo em que supre as matérias-primas que abastecem os luxos de todos os outros membros da coletividade (common wealth), e sustenta sobre os ombros, por assim dizer, toda a malha da sociedade humana, ele próprio, contudo, parece

${ }^{12}$ SMITH, Wealth of nations, p. 10 
ser oprimido pelo peso dessa estrutura para baixo da terra, até a profundeza de suas fundações, onde permanece, longe dos olhares. Em meio a tão opressiva desigualdade, como explicar a grande riqueza e abundância em que comumente vive até mesmo este mais baixo e mais depreciado membro da sociedade civilizada, em comparação com o que pode conseguir um selvagem, por mais respeitado e ativo que seja? ${ }^{13}$

A opulência da sociedade comercial, portanto, carrega consigo a exploração, a opressão, o menosprezo, ao menos no que concerne à maior parte da população. Com o "progresso", o lazer, de que todos desfrutam nas sociedades "selvagens", passa a concentrarse apenas nas camadas superiores da população:

Nas nações civilizadas, as camadas inferiores do povo têm muito pouco tempo livre, e as camadas superiores desfrutam de muitos [...] divertimentos. [Já] entre as nações selvagens, a grande massa da população tem frequentemente grandes períodos de tempo livre [...], portanto eles naturalmente despendem grande parte de seu tempo [...] com [a música e a dança $]^{14}$.

Além de perder lazer, com a divisão do trabalho a maior parte da população, os trabalhadores, perdem também capacidades associadas ao entendimento:

Com o avanço da divisão do trabalho, a ocupação da maior parte dos que vivem do trabalho, isto é, a grande massa do povo, passa a restringir-se a algumas poucas operações muito simples, frequentemente não mais que uma ou duas operações. Mas os entendimentos da maior parte dos homens são necessariamente formados por suas ocupações ordinárias. O homem que passa a vida inteira a realizar umas poucas ocupações simples, cujos efeitos são provavelmente os mesmos sempre, (...) não tem ocasião para exercer seu entendimento, ou para exercitar sua inventividade na descoberta de meios para superar dificuldades, já que estas nunca ocorrem. Por consequência, ele perde o hábito desse exercício, e geralmente se torna tão estúpido e ignorante quanto é possível que um ser humano se torne ${ }^{15}$.

Nem mesmo os "grandes e poderosos" vivem tão bem quanto se imagina, pois, segundo Smith, a felicidade de que eles parecem desfrutar é, de fato, uma ilusão daqueles que os observam:

${ }^{13}$ SMITH, "Early draft", pp. 563-564.

14 SMITH, Essays on philosophical subjects, p. 187.

${ }^{15}$ SMITH, Wealth of nations, pp. 781-782. 
Quando consideramos a condição dos grandes, nas cores ilusórias com que nossa imaginação tende a pintá-la, ela parece ser quase a ideia abstrata de um estado de perfeição e felicidade ${ }^{16}$.

Mas, de fato, o prazer ou bem-estar de que os afortunados gozam no usufruto de seus luxos pode ser menor do que o que os trabalhadores têm com seus confortos singelos:

Qual é $(. .$.$) a causa de sermos avessos à (...) condição [do trabalhador$ comum], e por que os que se criaram nas camadas mais elevadas (...) consideram pior do que a morte ver-se reduzidos a viver, mesmo sem ter de trabalhar, com a mesma simplicidade que ele, a habitar sob o mesmo teto baixo e cobrir-se com as mesmas humildes vestes? Imaginam que seus estômagos estejam melhores ou seu sono seja mais saudável em um palácio do que em uma cabana? O contrário tem sido tão frequentemente observado, e, mesmo que não o tivesse sido, na verdade é tão óbvio (...) que ninguém o ignora ${ }^{17}$.

Visto por esse ângulo, o tempo, em Smith, se assemelharia à imagem do tempo enquanto Kronos - ou declínio, e poderíamos muito bem concordar com Edwin West (1975), em seu artigo Adam Smith and Alienation. Wealth Increases, Men Decay?, para quem, de fato, Adam Smith nos pinta um quadro em que o avanço econômico é correlato ao declínio humano ${ }^{18}$.

No entanto, essa concepção não nos parece fazer jus inteiramente ao pensamento de Smith. Parece-nos mais preciso afirmar que para o filósofo, na marcha da humanidade muito se perde e muito se ganha. Se, por exemplo, em suas Considerações sobre a primeira formação das línguas, as línguas perdem em doçura ${ }^{19}$ e eloquência, ganham em clareza, e isso as torna acessíveis a falantes não nativos ${ }^{20}$. Ganha, portanto, a humanidade em conhecimento, com o intercâmbio entre os povos. Se a música já não nos é espontânea e familiar ${ }^{21}$, torna-se, contudo, conhecida e cultivada ${ }^{22}$.

O que, então, ganha a humanidade com o estabelecimento da sociedade comercial?

${ }^{16}$ SMITH, The theory of moral sentiments, pp. 51-52. Grifo nosso.

${ }^{17}$ SMITH, The theory of moral sentiments, p. 50. Grifo nosso.

18 WEST, “Adam Smith and alienation...”, 1975.

${ }^{19}$ SMITH, "Considerations concerning the first formation of languages", pp. 224-225.

${ }^{20}$ SMITH, "Considerations concerning the first formation of languages", p. 220, 222, 223.

${ }^{21}$ SMITH, "Of the imitative arts", p. 187.

$22 \mathrm{O}$ seu argumento, segundo o qual "não é por imitação que a música instrumental produz seu efeito", mas sim por ser ela mesma "um objeto alegre, tranquilo ou melancólico" (SMITH, "Of the imitative arts", p. 198), mostra a intenção de seu próprio texto de ser um avanço no conhecimento do que é a música. Por outro lado, a figura do "compositor", tão louvada por ele, corresponde a um artista refinado, dotado de "gosto, sensibilidade, fantasia e imaginação" (Idem, p. 200), portanto muito mais aperfeiçoado em sua arte do que se poderia esperar das “nações selvagens” em que a música primeiro se inventou (idem, p. 187). 
Sobretudo, ela realiza, segundo Smith, as mais importantes finalidades da natureza, inscritas em nós como um "desejo", a conservação do indivíduo e a propagação da espécie. Em suas palavras,

A auto-preservação e a propagação das espécies são as grandes finalidades que a natureza parece ter proposto na constituição de todos os animais. A humanidade é dotada do desejo destes fins, e de aversão pelo oposto ${ }^{23}$.

E se a sociedade comercial traz inquestionáveis ganhos coletivos, para além de toda a corrupção que a acompanha, o caso não é inteiramente diverso em relação aos indivíduos. Estes também, de certo modo, se dignificam, mesmo que às custas da felicidade. Modéstia, conhecimento, indústria, constância, resolução, firmeza, bom julgamento, habilidades, prudência, temperança, aplicação e autoconhecimento, todas essas qualidades virtuosas e dignificantes se difundem pela "vasta maioria da humanidade"24.

Nas palavras de Charles Griswold,

Consideradas conjuntamente, a Teoria dos sentimentos morais e a Riqueza das nações constituem-se em partes complementares de um conjunto maior [...] [que] sustenta uma visão não-sentimental da vida decente e produtiva do não-filósofo. Smith procura desenvenenar a busca por riqueza e fornecer uma defesa limitada de suas virtudes $[\ldots]^{25}$.

Não se trata, segundo o comentador, de virtudes "elevadas", mas de "virtudes medianas", próprias ao "homem prudente" - as quais, no entanto, são necessárias ao bem público, e dignas de aprovação, ainda que mereçam apenas uma "estima fria", isto é, não entusiástica ${ }^{26}$.

Nesse contexto, não se pode falar em "ocasião nefasta” em Smith do mesmo modo como em Rousseau, ou seja, como o espaço da ação política que participa da realização do tempo enquanto Kronos, enquanto declínio ou corrupção, já que para Smith aprimoramento e corrupção andam sempre juntos na história humana, com um "final feliz", ainda que pouco entusiasmante.

Poderemos, então, falar de um kairos, isto é, o espaço da ação política que seja benéfica à sociedade?

Pode-se dizer que, se o progresso "natural" da humanidade tem um sentido majoritariamente positivo para Smith, o espaço da política será antes o de impedir eventuais desvios do que o de promover avanços. Seja porque já há uma sociabilidade e uma justiça

${ }^{23}$ SMITH, The theory of moral sentiments, p. 77.

${ }^{24}$ SMITH, The theory of moral sentiments, p. 63.

25 GRISWOLD, Adam Smith and the virtues of enlightenment, p. 265.

${ }^{26}$ GRISWOLD, Adam Smith and the virtues of enlightenment, pp. 263-264. 
anteriores a qualquer governo civil $^{27}$, calcados em nossos sentimentos morais, seja porque na busca de seus próprios interesses cada qual acaba por promover os interesses coletivos, ao que se associa a clássica metáfora da mão invisível ${ }^{28}$. Nesse sentido, o papel do estado é bastante moderado, quase restrito ao estabelecimento e sistematização de regras que permitam a boa fluência do movimento natural da sociedade.

Há, no entanto, um espaço maior para a ação política: a prevenção ou remediação dos males decorrentes do próprio avanço da humanidade. É por isso que no livro $\mathrm{V}$ da Riqueza das Nações, e particularmente ao longo de toda a seção intitulada "Dos gastos das instituições para a educação da juventude", Adam Smith propõe, por exemplo, um sistema público de educação, a fim de minimizar os já mencionados prejuízos ao entendimento dos trabalhadores que podem resultar da subdivisão do trabalho ${ }^{29}$. Ali mesmo propõe, igualmente, que o estado "incentive" os que, "sem escândalo ou indecência", proporcionem cultura e lazer ao público, "por meio da pintura, da poesia, da música, da dança e de toda sorte de representações dramáticas", a fim de evitar a "melancolia e a disposição tristonha" que "nutrem a superstição e o entusiasmo" 30.

Aparentemente, portanto, a boa política se reduziria a não atrapalhar o "progresso", resultante das propensões da natureza humana; ou a contornar os males dele consequentes, com a menor intervenção possível. Nesse sentido, Adam Smith se enquadraria na critica às doutrinas iluministas do progresso segundo a qual as

Concepções iluministas da história [...] pecam pelo seu universalismo e pelo seu caráter abstrato, tomando, seja o gênero humano e sua totalidade, o que tem como resultado ignorar a particularidade dos povos, seja considerando os povos enquanto um todo harmônico, ocultando os conflitos e contradições no interior destes mesmos povos $[. . .]^{31}$.

Se esse enquadramento, contudo, não é cabível quanto a Rousseau, como demonstrou Maria das Graças de Souza, também não o será inteiramente quanto a Smith. É verdade que existe no pensamento do autor a prevalência de uma certa ideia de harmonia no interior de uma sociedade e entre as sociedades ao longo do avanço da humanidade, assim como tende a prevalecer a universalidade sobre a particularidade. Porém, como veremos, há conflitos, assim como há particularidades - Smith não os oculta.

Há conflitos. Na conclusão do Livro I da Riqueza das nações, o autor alerta enfaticamente para o conflito que existe entre o "interesse geral da sociedade" e o interesse de setores da economia. Segundo ele, o produto total da terra e do trabalho de um país se

${ }^{27}$ Cf. SMITH, The theory of moral sentiments, pp. 09, 80-81.

${ }^{28}$ Cf. SMITH, An inquiry into the nature and causes of the wealth of nations, p. 456.

${ }^{29} \mathrm{Cf}$. SMITH, An inquiry into the nature and causes of the wealth of nations, pp.782, 784-785.

${ }^{30} \mathrm{SMITH}$, An inquiry into the nature and causes of the wealth of nations, p.796.

31 SOUZA, “Ocasião propícia, ocasião nefasta”, p. 255. 
divide em três partes: a renda da terra, apropriada pelos proprietários de terras, os salários, apropriados pelos trabalhadores, e os lucros, apropriados pelos proprietários de capital. "O interesse dos primeiros", afirma ele, "é estritamente indissociável do interesse geral da sociedade", pois, quanto maior a prosperidade da nação, maior é o valor do produto da terra, e maior é sua renda; infelizmente, a ociosidade dessa ordem de pessoas as torna incapazes de discernir seu verdadeiro interesse ${ }^{32}$.

O interesse da segunda ordem de pessoas, os trabalhadores, também coincide com o interesse geral da sociedade, pois quanto maior for a prosperidade da nação, mais elevados serão os salários. Entretanto, eles também, por sua condição, não são capazes de bem julgar as questões públicas ${ }^{33}$.

O interesse dos proprietários de capital, porém, tende a não coincidir inteiramente com os interesses gerais da sociedade, pois "a taxa de lucro", afirma Smith,

Contrariamente à renda da terra e aos salários, não sobe com a prosperidade e cai com o declínio da sociedade; ao contrário, é naturalmente baixo nos países ricos e alto nos pobres, e atinge o seu nível mais alto nos países que mais rapidamente se dirigem para a ruína ${ }^{34}$.

Apesar disso, os proprietários de capital sempre buscam, com grande eficácia, convencer o público de que seus interesses e os da sociedade coincidem. É por isso que

Qualquer proposta de uma nova lei ou regulação comercial que venha dessa ordem deve sempre ser escutada com grande precaução, e nunca deve ser adotada antes de ser longa e cuidadosamente examinada, não apenas com a mais escrupulosa atenção, mas com a maior suspeita. Ela vem de uma ordem de homens cujo interesse nunca é exatamente o mesmo que o do público, que geralmente tem interesse em lograr e até oprimir o público, e que de fato tem em muitas ocasiões conseguido fazê-lo ${ }^{35}$.

Abre-se aqui o espaço, portanto, para a política em meio ao conflito, e, note-se, um conflito muito peculiar, pois a ordem dos proprietários de capital, que é a maior responsável pela prosperidade das nações, não é, todavia, interessada nessa mesma prosperidade. $O$

32 SMITH, An inquiry into the nature and causes of the wealth of nations, p.265.

${ }^{33} \mathrm{CF}$. SMITH, An inquiry into the nature and causes of the wealth of nations, p.266.

${ }^{34}$ SMITH, An inquiry into the nature and causes of the wealth of nations, p.266.

35 SMITH, An inquiry into the nature and causes of the wealth of nations, p.267. 
monopólio e as barreiras ao livre comércio são seus maiores interesses, e os que mais prejudicam a prosperidade social.

Esse conflito tem configurações particulares segundo as condições específicas de cada nação. Cada povo ou nação tem diferentes configurações de interesses, bem como diferentes hábitos e concepções que influenciam as decisões políticas, e nem sempre são os mais adequados para a boa constituição do estado ou a prosperidade social. É aqui que talvez se abra o maior espaço para a ação política construtiva, segundo as particularidades de cada nação ou povo. Na Teoria dos sentimentos morais Smith nos dá uma indicação disso ao tratar de dois caracteres opostos de pessoas públicas ou políticos. Um é o político de espírito público; outro, o homem de sistema. Segundo o filósofo,

O homem cujo espírito público é guiado inteiramente pela humanidade e pela benevolência, respeitará os poderes e privilégios estabelecidos, mesmo os de indivíduos, e mais ainda os das grandes ordens de sociedades em que se divide o estado. Mesmo que considere algumas delas em alguma medida abusivas, restringir-se-á a moderar o que muitas vezes não pode aniquilar, a não ser com grande violência. Quando não puder conquistar pela razão e pela persuasão as prevenções arraigadas no povo, não tentará subjugá-los pela força; antes observará religiosamente aquilo que Cícero chamou de a máxima divina de Platão: nunca usar de violência contra seu país, não mais do que contra seus pais. Ele acomodará, tanto quanto possa, a ordenação pública aos hábitos e prevenções consolidados no povo, e remediará como puder os inconvenientes que possam advir da falta das regras às quais o povo não aceita submeter-se. Quando não puder estabelecer o certo, não desdenhará melhorar o errado; mas, tal como o fez Sólon, quando não puder estabelecer o melhor sistema de leis, procurará estabelecer o melhor que o povo possa aceitar. ${ }^{36}$

Vê-se, portanto, que, sem deixar de se orientar por princípios, o político de espírito público é sobretudo um conciliador e um negociador arguto. No extremo oposto, temos o "homem de sistema", que, "muito sábio, segundo o conceito que faz de si mesmo", é irredutível na execução de seu próprio "plano ideal de governo", em total desconsideração aos "grandes interesses ou às fortes prevenções que possam a ele se opor".

Ele parece imaginar que pode arranjar os diferentes membros de uma grande sociedade tão facilmente quanto sua mão arranja as diferentes peças de um tabuleiro. Não considera que as peças do tabuleiro não têm outro princípio de movimento que não aquele que a mão lhes imprime; mas no grande

${ }^{36}$ SMITH, The theory of moral sentiments, p. 233. 
tabuleiro da sociedade humana, cada peça tem seu próprio princípio de movimento, inteiramente diverso daquele que a legislatura possa escolher imprimir-lhe. Se esses dois princípios coincidirem e atuarem na mesma direção, o jogo da sociedade humana prosseguirá com tranquilidade e harmonia, e muito provavelmente será feliz e exitoso. Caso sejam opostos ou diferentes, o jogo prosseguirá pessimamente, e a sociedade se encontrará a todo momento no mais alto grau de desordem. ${ }^{37}$

Podemos afirmar, assim, que em Adam Smith o kairos, ou ocasião oportuna, pede uma intervenção discreta, "homeopática", que se oriente por princípios, mas que leve em consideração como, e em que medida, estes podem aplicar-se, segundo a configuração dos interesses e as características do povo que constituem o objeto de sua prática. A ação política, portanto, não é imediatamente decisiva para mudar os rumos de uma nação, a não ser quando é dogmática, caso em que pode desviar a nação do rumo do progresso. Quando favorável ao avanço, a ação política parece ser, para Adam Smith, uma construção paciente e sagaz para eliminar obstáculos ou favorecer a tendência "natural" ao progresso. De alcance limitado, objeto de cautela, a política, na concepção do filósofo escocês, se assemelha mais a uma administração ou gestão do que a uma ação fundante de uma ordem social.

\section{NATURAL PROGRESS AND POLITICAL ACTION IN ADAM SMITH}

Abstract: This text retakes the questions proposed by Maria das Graças de Souza concerning Jean-Jacques Rousseau and try to verify whether they apply or not to Adam Smith's thought. According to the author, in Rousseau's thought there are two conceptions of historical time: one of them as determination (i.e., as decline); and the other as "opportune occasion", i.e. the moment of political action. In Adam Smith, on the other hand, history does not appear as decline, but rather as a "natural progress", and thus as determination. We try to show, however, that the author also sees the need for political action, albeit with many restrictions. Keywords: A. Smith -J-J. Rousseau - natural progress - political action.

\section{REFERÊNCIAS BIBLIOGRÁFICAS}

ARTIÈRES, P. "Dizer a atualidade: o trabalho de diagnóstico em Michel Foucault". In: Foucault: a coragem da verdade. GROS, F. (Org.). São Paulo: Parábola Editorial, 2004.

GRISWOLD, Charles L., Jr. Adam Smith and the virtues of enlightenment. Cambridge: Cambridge University Press, 1999.

MAROUBY, Christian. L'économie de la nature. Paris: Éditions du Seuil, 2004.

${ }^{37}$ SMITH, The theory of moral sentiments, pp. 233-234. 
SMITH, Adam. An inquiry into the nature and causes of the wealth of nations. Indianapolis: Liberty Fund, 1979.

. "Considerations concerning the first formation of languages". In: Lectures on rhetoric and belles lettres. Oxford: Oxford University Press, 1983. Pp. 201-226.

. "Early draft of part of The Wealth of Nations". In: Lectures on jurisprudence. Oxford: Oxford University Press, 1978. Pp. 562-580.

Essays on philosophical subjects. Oxford: Oxford University Press, 1980.

Lectures on jurisprudence. Oxford: Oxford University Press, 1978.

. Lectures on rhetoric and belles lettres. Oxford: Oxford University Press, 1983.

. "Of the imitative arts". In: Essays on philosophical subjects. Oxford: Oxford University Press, 1980. Pp. 176-209.

The theory of moral sentiments. Indianapolis: Liberty Fund, 1979.

SOUZA, Maria das Graças de. "Ocasião propícia, ocasião nefasta: Tempo, história e política em Rousseau”. Revista Trans/form/ação, UNESP, Marília, vol. 29, n. 2, 2006.

WEST, Edwin G. "Adam Smith and alienation: Wealth increases, men decay?”. In: Essays on Adam Smith. SKINNER, A. S. e WILSON, T. (Orgs.). Oxford: Clarendon Press, 1975. Pp. 540-552. 